\title{
Publication Trends in West Indian Medical Journal: A 12-year Bibliometric Study Populates an Ontology
}

TA Richards ${ }^{1}$, S Muehlenbacher ${ }^{2}$, F Weichert ${ }^{3}$, M Wagner ${ }^{4}$

\begin{abstract}
Objective: Formal specifications of scientometric data representing a journal's output were to be generated.

Methods: Individual print issues of the West Indian Medical Journal (WIMJ) from 2001 to 2012 were perused. An ontology was populated with the results in accordance with the web ontology language description logic (OWL DL) format.

Results: Scientometric data could be obtained from the 1332 articles published by the WIMJ and entered into an ontology. The current approach did not however allow the conversion of textual nuances into code considered compliant with the OWL DL format.

Conclusion: West Indian Medical Journal has shown an increasing trend in the number of published articles over the last twelve years. It is possible to generate an ontology that could support future modelling and simulation. The authors' attempts to remain fully compatible with the OWL DL format did not support the representation of textual nuances.
\end{abstract}

Keywords: Bibliometric study, publication trends, systems biology, West Indian Medical Journal

\section{Tendencias en las Publicaciones de West Indian Medical Journal: un Estudio Biblio- métrico de 12 Años Suministra datos para una Ontología}

TA Richards ${ }^{1}$, S Muehlenbacher ${ }^{2}$, F Weichert ${ }^{3}$, M Wagner ${ }^{4}$

\begin{abstract}
RESUMEN
Objetivo: Generar las especificaciones formales de datos cienciométricos que representan la producción de la revista.

Métodos: Se examinaron ediciones impresas individuales de West Indian Medical Journal (WIMJ) de 2001 a 2012. Una ontología fue creada con los resultados de acuerdo con el formato OWL DL.

Resultados: Datos cienciométricos pudieron ser obtenidos a partir de los 1332 artículos publicado por la WIMJ y conformados en una ontología. Sin embargo, el enfoque actual no permitió la conversión de los matices textuales en un código que cumpliera con las exigencias del formato de OWL DL.

Conclusión: La revista West Indian Medical Journal ha mostrado una tendencia creciente en el número de artículos publicados en los últimos doce años. Es posible generar una ontología que podría servir de apoyo para una futura modelización y simulación. Los intentos de los autores por permanecer totalmente compatibles con el formato de OWL DL no se corresponden con la representación de matices textuales.
\end{abstract}

Palabras claves: Estudio bibliométrico, tendencias de publicación, biología de sistemas, West Indian Medical Journal

West Indian Med J 2016; 65 (3): 486

From: ${ }^{1}$ Medical Branch Library, UWI, Kingston 7, Jamaica, West Indies, ${ }^{2}$ Department of Pathology, University of Saarland, Homburg Saar, Germany, ${ }^{3}$ Department of Computer Science VII, Technical University Dortmund, Dortmund, Germany and ${ }^{4}$ Department of Pathology, University of Saarland, Homburg Saar, Germany.

Correspondence: Ms TA Richards, Medical Branch Library, The University of the West Indies (UWI), Mona Campus, Kingston 7, Jamaica, W.I. Fax: (876) 970-0819; e-mail: tereza.richards@uwimona.edu.jm

\section{INTRODUCTION}

When The University of the West Indies (UWI) was established in 1948 as a College of the University of London, it was the Faculty of Medicine that constituted the single faculty with 33 medical students enrolled. From the outset, it was determined that a journal of medicine associated with the new University College would be established which would be scholarly, peer reviewed and cover the entire Caribbean (1). 
The West Indian Medical Journal (WIMJ) was the result of this proposed initiative. First published in 1951, it expanded on the medical journal of the day, Jamaica Medical Review which had, as its focus, medical problems in Jamaica, to become a forum for the exchange of information on research conducted primarily in and covering the wider Caribbean. The WIMJ became of value to regional and international clinicians, scientists, healthcare planners and researchers as an organ that chronicled the history of diseases in the Caribbean and monitored the epidemiological transition from infectious diseases to current lifestyle related diseases (2).

The Journal publishes twelve issues and six supplements annually containing original scientific research, reviews, case reports, brief communications, letter and commentaries (3). It has acquired a reputation over the years of being one which publishes original articles with diversified content (4).

Scientometrics, bibliometrics, informetrics, information metrics, iMetrics and webometrics have similar objectives and methods, namely using mathematics (including statistics) to analyse scientific output. They may therefore all be considered as manifestations of a single area of research, for simplification in the present study referred to as "bibliometrics". Researchers can examine literatures and establish characteristics of disciplines, obsolescence of scholarship, institutional affiliations and relationships and types of materials constituting scholarly pursuits (5).

Bibliometric analyses are based on the assumption that carrying out research and communicating the results go hand in hand. Publications, most commonly in the form of referred articles or scholarly monographs, may be regarded as the definitive statements of the results of research projects. This production can be quantified and analysed to determine the size and nature of the research carried out at macro level to measure global, regional, or national trends or at the micro level of institutions or groups (6).

A bibliometric analysis can therefore indicate trends and patterns, within scientific disciplines or as in this case within a particular journal by examining the number of articles published, by which authors and the territories they are associated with as important gauges of the journal's influence and impact (7). Mathematical models in bibliometrics may provide the framework for a common body of knowledge that can be considered characteristic of this area of research (8).

Ontologies, in the present study represented by an OWL document, may be considered one of the pillars of the Semantic Web as they provide both human-readable and computerusable definitions of basic concepts in a domain and the relationships among them, resulting in shared models of that domain by encoding views common to a set of different parties (9). The present study was therefore conducted to determine whether an ontology applicable to future mathematical modelling can be populated from a bibliometric description of the WIMJ without considerable loss of information.

\section{MATERIALS AND METHODS}

West Indian Medical Journal issues for January to December of 2001 to 2012 (volumes 50 to 61; excluding supplements), were manually perused to analyse the publication trends of the journal. The following document types were included for the analysis: editorial, special communication, special article, viewpoint, original article, CME image and diagnosis, case report, clinico-pathological conference presentation, letter to the editor, dental forum, medical history, short communication, short report, nephrology forum, research letter, review article and continuing medical education. The types of articles excluded were: book review, obituary, medical students' forum, errata, colloquia, tribute, special message, lectures, reprinted article, preface and forthcoming events. Each article was graded to ascertain type of article, place where the research originated determined by the address of the corresponding author, collaboration based on the number of authors, the territories the co-authors were associated with, medical specialties, and institutional affiliation of the corresponding author.

An ontology of the Food and Agriculture Organization of the United Nations (FAO), the FAO GEOPOLITICAL ONTOLOGY (10) and a common ontology of scientific experiments, the EXPERIMENT ONTOLOGY 2.0 [EXPO 2.0] (11), were merged using PROTÉGÉ 4 (12), an open source ontology editor which supports the creation of OWL DL 2.0 based-class and subclass tree structures. Subsequently, a novel ontology based on these two frameworks was interactively populated by generating classes that represented subjects and types of articles as well as authorship types. The basic class hierarchy structure divided areas, authors, journals, article subjects and journal articles. An object property called has country of origin connected classes of authors to the names of specific territories taken from the FAO GEOPOLITICAL ONTOLOGY to link the location of the affiliation to the author types. Authors were "anonymized" as there was no expression to represent any author's name or actual nationality. Among the new entries, only the object property country hosting the affiliation and the data property has number of authors were enriched through the use of property characteristics (they were defined as functional, $i e$, having at most one outgoing connection). The cardinal restriction "exactly" specified quantities and connected them with the corresponding classes.

The results were subsequently analysed for domain adequacy by expert knowledge. Two description logics reasoners, FACT++ and PELLET 2.0, embedded in PROTÉGÉ as plugins, were run to check the logical consistency of the ontology. The framework was furthermore tested by the online University of Manchester OWL Validator 2009 (13) to detect a possible lack of coherence with the OWL 2 profile.

\section{RESULTS}

Over the 12-year period 1332 articles were published in WIMJ (mean, 111; median, 108; mode, 117; and range, 154-79=75; Fig. 1). It should be noted that volumes 50 to 52 published 


\section{Article Type}

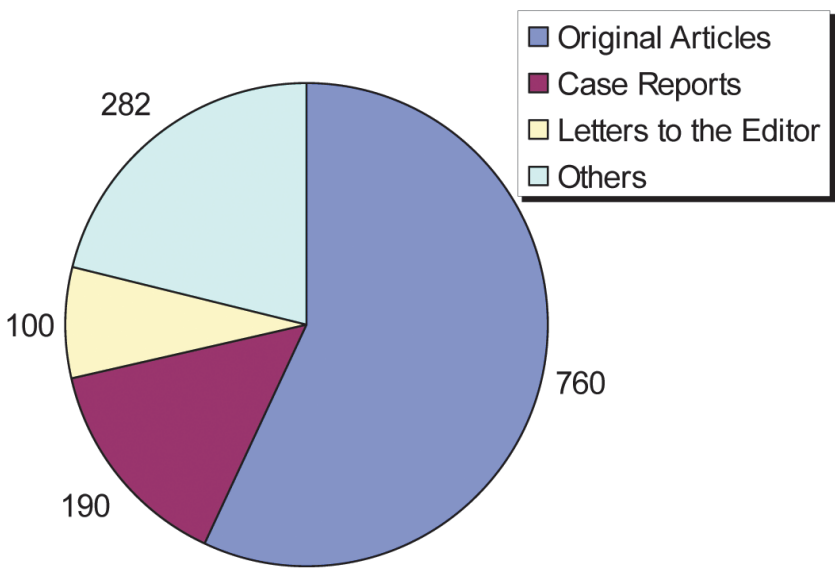

Fig. 1: Twelve years' output of the West Indian Medical Journal (WIMJ). A total of 1332 articles were published in WIMJ over the 12-year period. It included for example 760 original articles.

four issues each year and beginning in 2004 with volume 53 there were six issues published each year. The articles published represented 19 different types, and the highest number of articles published were original articles, followed by case reports and letters to the editor. There has been steadily increasing output over the years ranging from 79 articles in 2002 to 154 in 2010.

The articles came from 51 different territories (including those in the Caribbean) representing all continents and were the territories the corresponding authors were associated with indicated (Fig. 2). When the geographic spread of the research was examined through the territories attributed to the

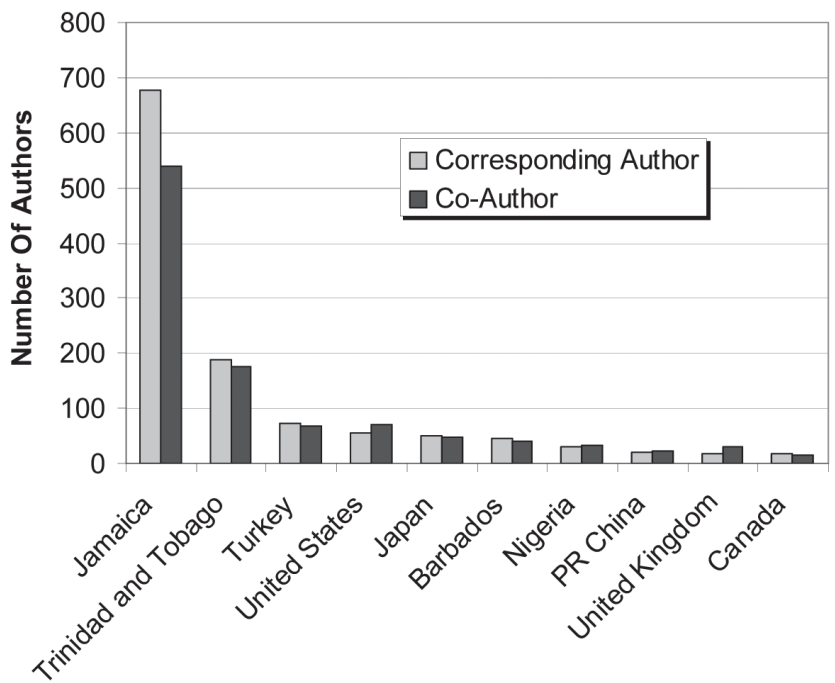

Location of Affiliation

Fig. 2: The ten highest producing territories for the WIMJ by corresponding authors. Ranking for co-authorship differed from the one by corresponding authors in that Turkey and the United States changed positions. This also applied to the People's Republic of China ("China") and the United Kingdom. co-authors (ie the number of times various geographic regions were listed as the territories the co-authors were associated with), there were 60 different territories listed (the 10 highest producing with regards to co-authorship were Jamaica 539; Trinidad and Tobago 176; the United States 71; Turkey 67; Japan 47; Barbados 41; Nigeria 33; the United Kingdom 30; People's Republic of China 22; and Canada 14).

Contributions from Caribbean territories outside of the three main UWI Campus territories and highest producing (Jamaica, Trinidad and Tobago and Barbados) indicate on average four articles. Contributions from territories outside the Caribbean are significant as on average from North America there are 23 articles, from Asia 19, from Africa 10, from Europe 5, and from South America 3.

The level of collaboration among authors (Fig. 3) had a mean of 83.25 (median: 29.5; mode: 1; range: $238-1=237$ ).

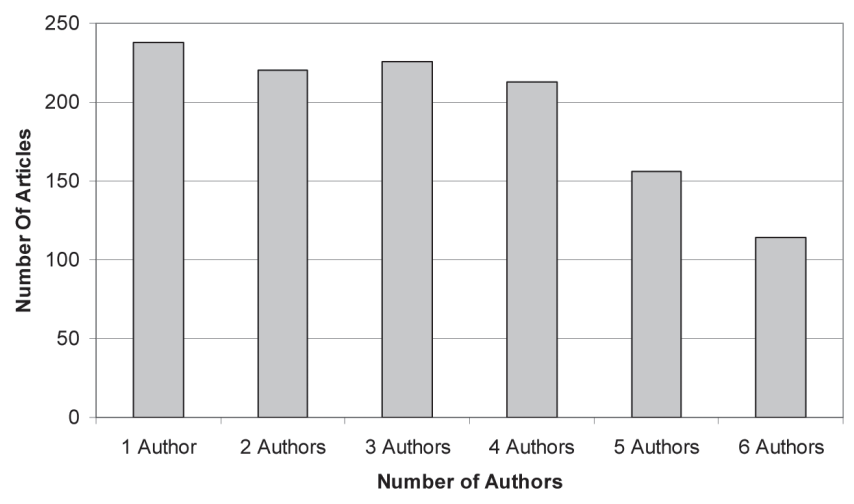

Fig. 3: The level of collaboration among authors in the WIMJ. The highest number for the category "authors per publication" was $n=238$. It applied to entries by one author while $n=220$ represented those by two, and $n=226$ held true for those presented by three authors.

The determination of whether the majority of the corresponding authors were affiliated to UWI or non-UWI institutions was considered with 809 articles $(\sim 60.7 \%)$ emanating from UWI affiliated authors and $523(\sim 39.3 \%)$ from non-UWI affiliated authors. The subjects covered a wide range of biomedical specialties with most contributions attributable to general medicine, followed by general surgery, paediatrics, psychiatry, pathology and others (Fig. 4).

EXPO 2.0 had 325 distinct classes, 78 object properties, 432 subclass axioms, 363 disjoint classes axioms, 76 subobject properties axioms, 75 object property domain axioms, 73 object property range axioms and an expressivity of $A L C H N$. FACT ++ and PELLET 2.0 confirmed its logical consistency. EXPO 2.0 was readily expandable by either adding new nodes or attaching whole new semantic networks to the system. The ontology was populated by combined representations of for example first authors, co-authors or corresponding authors with those of the territories hosting the authors' affiliations supported the generation of information triplets ("territory plus author status") by interconnection with other items (Fig. 5). 


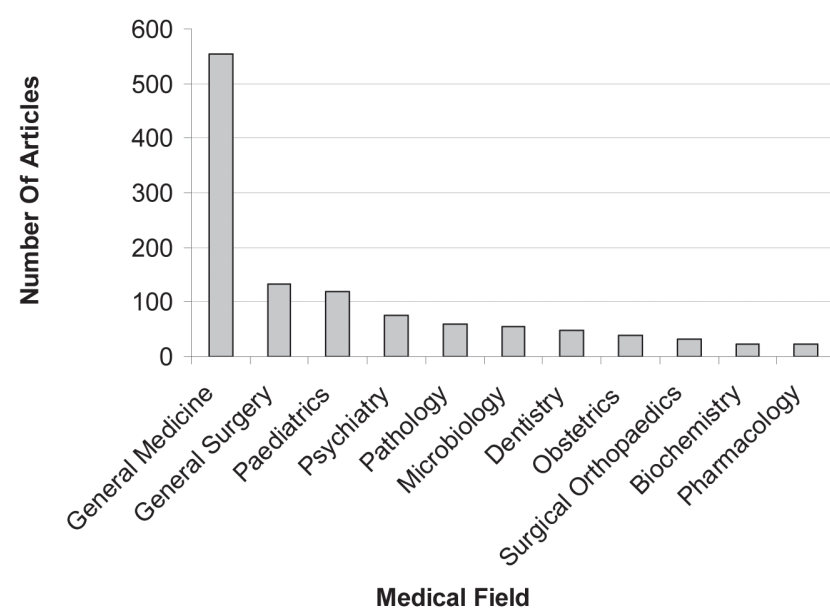

Fig. 4: Twelve years' contribution of specialties to the WIMJ. General medicine produced 555 articles while general surgery had 132, paediatrics had 119 , psychiatry 76 , pathology 59 , microbiology 56 , dentistry 49 , obstetrics 40 , surgical orthopaedics 31 and biochemistry and pharmacology both had 24 entries.

The resulting ".owl" file was termed "Bibliometric_Ontology". It contained 108 classes and 89 subclass axioms and had an expressivity of $A L C H O Q(D)$. It represented the results of the present bibliometric study ontologically (Fig. 6). Domain adequacy could be verified and both reasoners confirmed its logical consistency. The file was validated to be in the OWL 2 profile. The format may therefore be readily submitted to se-

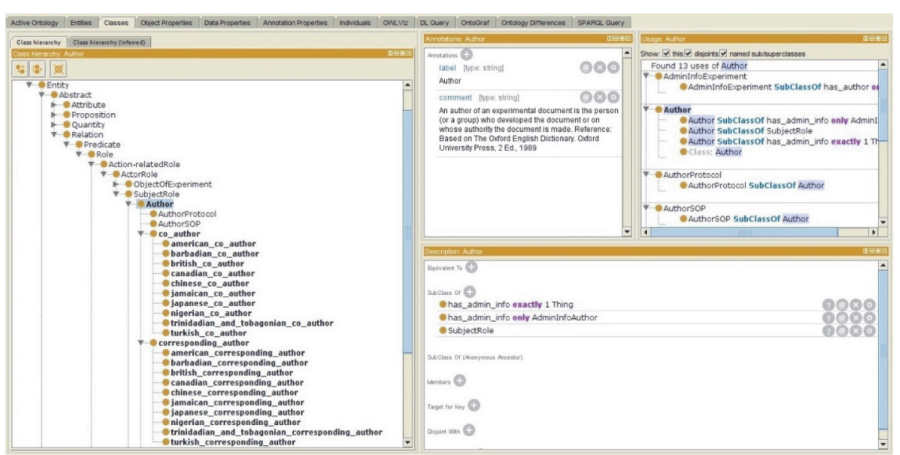

Fig. 5: Class hierarchy and class description view. Items were created combining information on authorship type and territories to allow the generation of "information multiples" consisting of an item which represents "author status plus territory" connected to other ontological classes. There were no expressions to describe nationalities.

mantic web applications for analysis and algorithms for computer-aided (eg systems biological) mathematical modelling. Frameworks like this would then serve as an input for example for future computer simulation. Nuances of information as provided by the two sentences right before the one you are currently reading could however not be converted into a syntax consistent with the OWL DL format. The authors of the present study were therefore populating an ontology based on a word-by-word approach. These word-by-word representations of relevant aspects extracted from the text corpus of the present study lead to considerably complex ontological structures (Fig. 7). The authors of this report are therefore planning

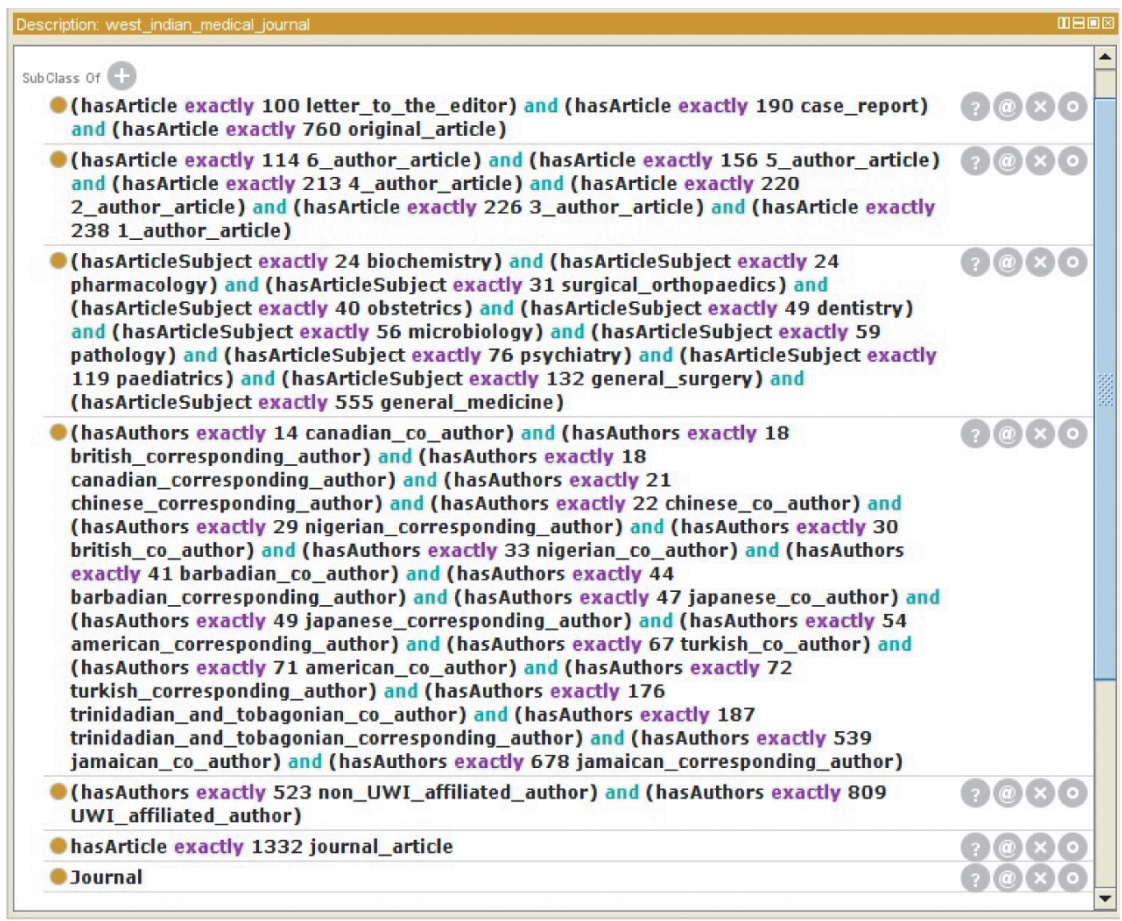

Fig. 6: Class description view of details of the WIMJ's contribution to the body of literature. Alphanumeric data provided in a format such that this may be processed farther using semantic web applications. 


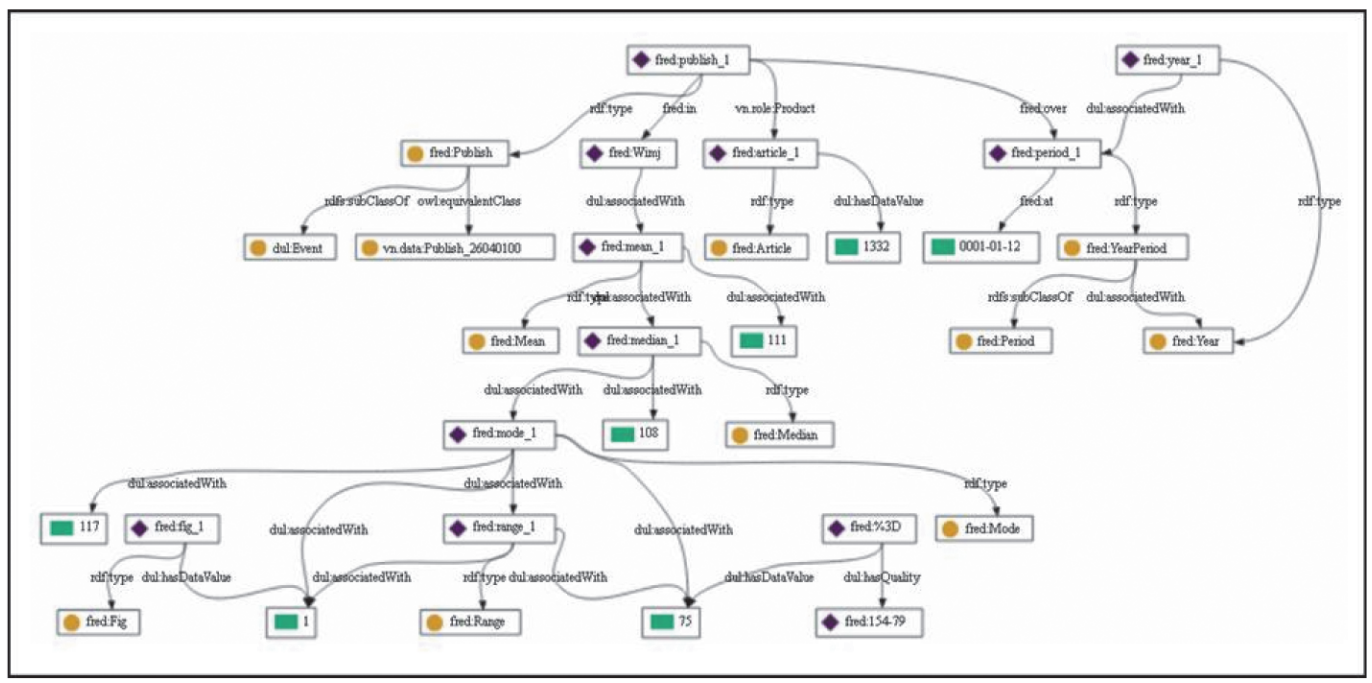

Fig. 7: Ontological representation of the total twelve years' output of the WIMJ. A text passage describing this condition can be found in the "RESULTS" section of this publication to state, "Over the 12-year period 1332 articles were published in WIMJ (mean, 111; median, 108; mode, 117; and range, 154-79 = 75; fig. 1)". It may be converted into a graph to support visual analyses of underlying concepts as disclosed by a combination of linguistic frame semantics, the Discourse representation theory (DRT), and ontology design patterns (ODP) (14). Pointing to this very figure for example was represented by the entity "fig._1" and its interrelations.

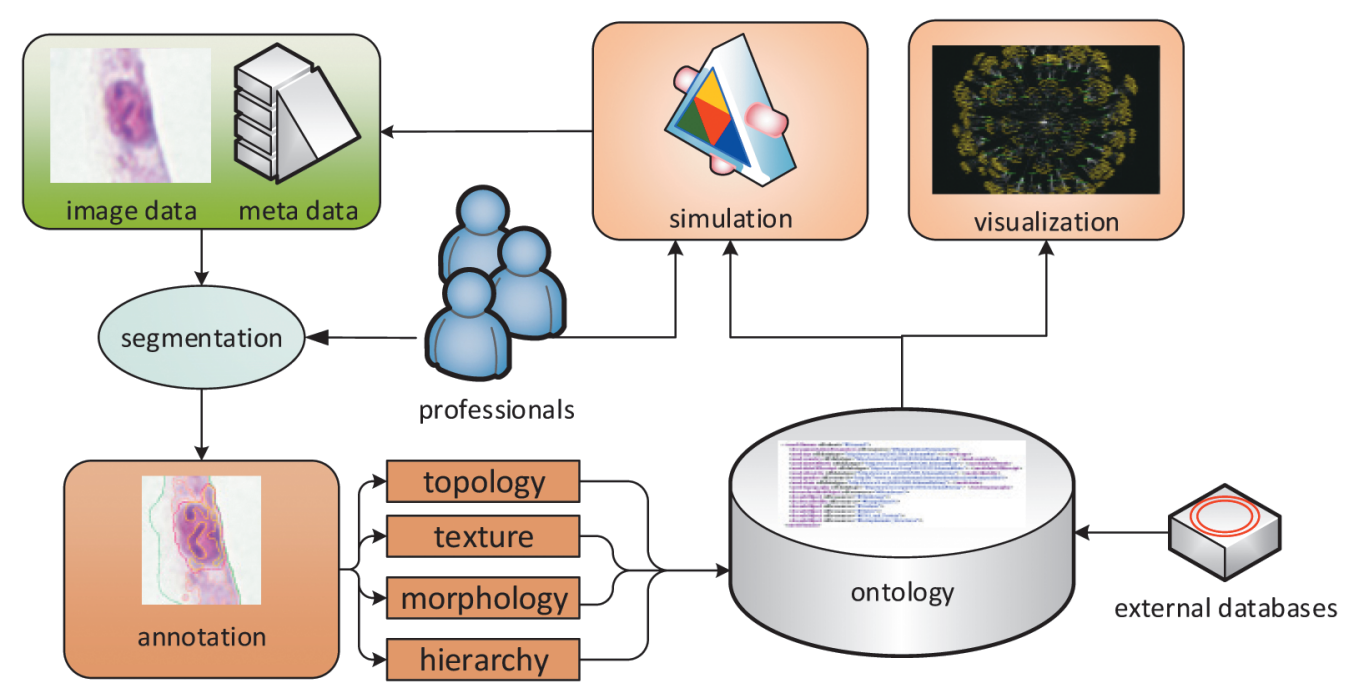

Fig. 8: Schematic representation of a conceptual pipeline for ontology-driven simulations. Features of for example bibliometric or image data may be used to populate an ontology. This framework when parameterised by domain experts and supplemented by external databases may constitute the basis for simulation.

to conduct studies aiming at simplification and dataset size reduction.

\section{DISCUSSION}

This study analysed the publication trends of WIMJ. Concomitant with the wide geographic spread of contributions evidenced by territories of first authors is a high level of collaboration indicated by the variety of territories the co-authors were associated with which speaks to international collabora- tion for research and publication of research output. Although it is an organ of the Faculty of Medical Sciences at the UWI there is a high representation of articles contributed from nonUWI affiliated authors.

Ontologies are conceptual models that capture and explain items and their interactions, hereby establishing a semantic foundation that may be used in mathematical modelling (15). They allow scientists in developing countries to expand frontiers of computing over the updatable semantic web by a 
low-budget approach. The ontology editor PROTÉGÉ constitutes an example of a collaborative freeware tool for managing such concepts. Some of the authors of the present analysis have recently introduced temporal ontologies to simulation, an approach applicable to the data presented in this report (Fig. 8). To their knowledge this constitutes the first attempt to generate a bibliometric ontology populated directly from a text file and have the bibliometric and ontological results published in the same article. Nuances of the text were not represented by the ontology. The authors of this report are therefore planning to compare the usefulness of the approach presented here with an approach still to be established which uses data obtained from a conversion of text corpora into ontologies on a wordby-word basis. Once converted into an ontology on a word-byword basis, the content of a publication is assumed to serve as an input in mathematical modelling without major loss of information. Systematic studies are warranted to evaluate the usefulness of such datasets.

\section{CONCLUSION}

West Indian Medical Journal is a forum for global dissemination of research and communication which speaks to its widespread influence and it is therefore not just reflective of Caribbean reach and appeal. Contribution to this journal comes from various continents indicating its global appeal as a vehicle for showcasing research and views of scientists from all over the world. The bibliometric findings can serve as an indicator for the journal's achievements to date and as a benchmark for future assessment and comparison with other journals.

Freeware may be used to generate ontologies from articles to generate a basis for mathematical modelling. Nuances of information may however be lost in attempts to remain fully compatible with the OWL DL format. Methods applicable to effectively populate ontologies with data extracted from text corpora on a word-by-word basis are therefore assumed to bridge that gap. Systematic studies on this issue are warranted in the context of ontology-driven mathematical modelling and simulation.

\section{REFERENCES}

1. Nettleford R. Vice Chancellor's Message. West Indian Medical J 2001; 50 (Suppl. 4): 2.

2. Barton E. Fifty years of the West Indian Medical Journal. West Indian Medical J 2001; 50 (Suppl. 4): 1.

3. University of the West Indies (Mona, Jamaica). About West Indian Medical Journal [Internet] Kingston, Jamaica: UWI Mona, 2014. [accessed 15 May 2014; cited 3 Sep 2014] Available from: http:// myspot.mona.uwi.edu/fms/WIMJ/about

4. Hall K. Principal's fiftieth anniversary message. West Indian Medical J 2001; 50 (Suppl. 4): 3.

5. Jacobs D. Demystification of bibliometrics, scientometrics, informetrics and webometrics. Paper presented at the 11th DIS Annual Conference 2010, 2-3 September, Richardsbay, University of Zululand, South Africa.

6. Russell J, Rousseau R. Bibliometrics and institutional evaluation. In: Encyclopedia of Life Support Systems (EOLSS), Developed under the Auspices of the UNESCO, EOLSS Publishers, Paris, France, [http:// www.eolss.net] 2002; 42-64.

7. Landoni G, Bignami E, Nicolotti D, Pieri M, Silvetti S, Buralti L. Publication trends in the Journal of Cardiothoracic and Vascular Anesthesia: a 10-year analysis. J Cardiothorac Vasc Anesth 2010; 24: 969-73.

8. Leimkuhler FF. On bibliometric modeling. Informetrics 1988; 87186: 97-104.

9. Maheswari UJ, Karpagam GR. Ontology based comprehensive architecture for service discovery in emergency cloud. Internat J Engineer Technol (IJET) 2014; 6: 242-51

10. Kim S, Iglesias-Sucasas M, Viollier V. The FAO Geopolitical Ontology: a reference for country-based information. J Agricult Food Inform 2013; 14: $50-65$.

11. Soldatova LN, King RD. An ontology of scientific experiments. J R Soc Interface 2006; 3:795-803.

12. Akinbode KB, Longe B, Omoifo OI. Constructing ontologies in OWl using Protégé 4. Afr J Comp ICT. 2011; 4: 23-6.

13. Tzoganis G, Koutsomitropoulos DA, Papatheodorou TS. Querying ontologies: retrieving knowledge from semantic web documents. Proc Panhellenic Stud Conf Inform (EUREKA 2009): 2009.

14. Draicchio F, Gangemi A, Presutti V, Nuzzolese AG (2013) FRED: from natural language text to RDF and OWL in one click. LNCS 7955: 2637

15. Miller J, Fishwick P. Ontologies for modelling and simulation: issues and approaches. In: Ingalls RG, Rossetti MD, Smith JS, Peters BA (eds) Proceedings of the 2004 Winter Simulation Conference, Orlando, FL, USA; pages 259-64.

16. Weichert F, Mertens C, Walczak L, Kern-Isberner G, Wagner M. A novel approach for connecting temporal-ontologies with blood flow simulations. J Biomed Inform 2013; 46: 470-9. 